Marcus Raitner works as an agile transformation agent and agile coach at BMW Group IT. In his blog "Experience leadership!" he has been writing about leadership, agility, digitalization, and much more since 2010.

\title{
Context Not Control
}

W

hat does Netflix have in common with a nuclear submarine? Although at first glance they couldn't be more different, they share an exceptional leadership culture. Reed Hastings, CEO of Netflix, prides himself on making as few decisions as possible and preferably none at all for an entire quarter. And Captain David Marquet decided to stop giving orders on the nuclear submarine USS Santa Fe. Both rely on context instead of control and are very successful with it.

For over a year David Marquet prepared himself for his new task as captain of the USS Olympia. He learned every detail about this nuclear submarine. Everything went as planned until he had to take command of the USS Santa $\mathrm{Fe}$ at short notice. And as the USS Santa Fe was a much newer type, David Marquet knew little about it when he took command.

Nevertheless David Marquet went to work and gave commands as captains are trained to do. After all the USS Santa Fe was at that time the submarine with the worst performance and morale in the Navy and therefore the situation demanded a strong leader. Didn't it?

During a drill in the first month of his command, David Marquet realized the danger of a team trained in obedience and a boss with limited knowledge. The drill simulated the failure of the main reactor and thus the USS Santa Fe had to run on a battery-powered electric propulsion motor until the reactor was repaired. To challenge the crew a little bit, David Marquet gave his officer of the deck the order "Two thirds ahead!" The officer immediately passed the order on to the helmsman and ... nothing happened!

When David Marquet asked the helmsman why he had not executed the order, he was told that - unlike on his previous submarines - on this ship there was no "twothirds ahead". Everyone on board knew this except David Marquet. Especially the officer of the deck knew this, but he nevertheless passed the order because he was trained in obedience. This was the moment when David Marquet realized that with his limited knowledge and experience he was a dangerous bottleneck, and at the same time he realized the potential hidden in the collective experience, intelligence and creativity of his crew. Potential he wanted to unleash.

After this epiphany he refused to give orders. Except for the use of nuclear missiles, David Marquet let his crew decide. In order to make these decisions he provided the full context and then acted as a coach. When an officer asked for permission to submerge the ship, for example, he made the officer think about whether it was safe on the one hand and on the other hand whether it was now the right thing to do in terms of the overall mission. Gradually fewer and fewer officers asked for permission, but began to think like David Marquet.

With this remarkable leadership style, David Marquet succeeded in turning the ship around (which is why his very recommendable book is entitled "Turn Around the Ship!"). The USS Santa Fe went from worst to best in the US Navy and remained so after David Marquet retired in 2009.

Despite this stunning evidence of the impact of this "leader-leader" paradigm (instead of the far more common "leader-follower" paradigm), examples of this leadership culture in large hierarchical organizations are still difficult to find. However, at Netflix, the seventh largest Internet company in the world, one will easily spot this in their legendary Culture Statement, which Patty McCord published as former Chief Talent (sic!) Officer in 2009. In the revised version on the Netflix website it becomes unmistakably clear who decides at Netflix and what the task of leadership is:

We want employees to be great independent decision makers, and to only consult their manager when they are unsure of the right decision. The leader's job at every level is to set clear context so that others have the right information to make generally great decisions.

Netflix Culture Statement

The book "Manifest für menschliche Führung" ("Manifest for human leadership") is available as paperback and e-book on Amazon 